International Journal of Current Advanced Research

ISSN: O: 2319-6475, ISSN: P: 2319 - 6505, Impact Factor: SJIF: 5.995

Available Online at www.journalijcar.org

Volume 6; Issue 4; April 2017; Page No. 3063-3065

DOI: http://dx.doi.org/10.24327/ijcar.2017.3065.0182

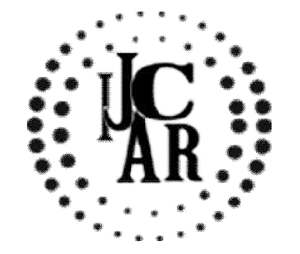

Research Article

\title{
INTERRELATIONSHIP BETWEEN OBESITY AND DENTAL CARIES- A PILOT STUDY
}

\author{
Samyukta $S$ and Gifrina Jeyraj
}

Saveetha Dental College \& Hospitals, Poonamallee By-pass Road, Chennai, Tamilnadu

\begin{tabular}{l}
\hline A R T I C L E I N F O \\
Article History: \\
Received $16^{\text {th }}$ January, 2017 \\
Received in revised form $7^{\text {th }}$ February, 2017 \\
Accepted $15^{\text {th }}$ March, 2017 \\
Published online $28^{\text {th }}$ April, 2017 \\
\end{tabular}

Key words:

Depression, Anxiety, dermatology, psychiatric

\begin{abstract}
A B S T R A C T
Aim: The aim of this study is to determine the relationship between the body mass index and dental caries amongst the out patient population of Saveetha Dental College.

Background: Dental caries is a multifactorial disease which is one of the most common infectious diseases occurring in the oral cavity. It refers to the demineralisation of the tooth by the bacteria. In recent times, due to the change in lifestyle and decrease in physical activity, the incidence of obesity is fast growing. Obesity occurs due to an imbalance in the caloric intake and energy expenditure. The bodies functioning is affected in various ways due to obesity.

Materials and Methods: The present study was conducted amongst 70 out patients, 35 male and 35 female, visiting saveetha dental college, chennai. The height of the subjects was calculated using a standard inch tape in Centimeters, and the weight was measured using a unicaliberated weighing machine in KiloGrams. The Body Mass Index of the subjects were then calculated using the height and weight. DMFT index was used to assess dental caries status in the subjects. The collected data was then analysed using SPSS software.

Results: There was no relationship between obesity and dental caries.
\end{abstract}

Copyright $\mathrm{C} 2017$ Samyukta S and Gifrina Jeyraj. This is an open access article distributed under the Creative Commons Attribution License, which permits unrestricted use, distribution, and reproduction in any medium, provided the original work is properly cited.

\section{INTRODUCTION}

Globally, non-communicable diseases are being recognized as a major cause of morbidity and mortality, the increasing burden of which, particularly in developing countries of Asia including India, threatens to overwhelm already stretched health services.(1) Among them, overweight and obesity are the most important. Multiple factors plays role in this 'nutritional transition' i.e., lack of physical activity, unhealthy eating patterns, or a combination of both with genetics and lifestyle playing important roles. Current researches in dental sciences trends toward exploring the link between and the true etiology of obesity (general health) and dental caries (oral health), which is complex and multifactorial. Many of the contributing factors are rooted in evolving lifestyle changes as well as ever-changing internal body and external environment. Overweight and obesity are multifactorial conditions involving physiological, biochemical, metabolic, anatomic, psychological, and social alterations (Taubes, 1998). Complications of the obesity epidemic include high cholesterol, high blood pressure, type II diabetes mellitus, coronary plaque formation, and serious psychosocial implications (AAP, 2004).

\section{*Corresponding author: Samyukta S}

Saveetha Dental College \& Hospitals, Poonamallee By-pass Road, Chennai, Tamilnadu
Obesity has reached global epidemic proportions, with more than 1 billion adults overweight-at least 300 million of them clinically obese- affecting virtually all ages and socioeconomic groups. (2) Dentists must be aware of how nutrition impacts on general and oral health and how dental treatment can impact on the patient's nutritional status (Romito, 2003). There is a growing awareness and sources of evidence of associations between higher and more regular Sugar Sweetened Beverages consumption and poorer general and oral health outcomes across a range of measures, including dental caries and obesity. (3)

Dental caries is a multifactorial infectious disease (Selwitz et al, 2007) the onset of which is influenced by oral hygiene, diet composition and frequency, socioeconomic status, salivary immunoglobulins, bacterial load and fluoride intake (Cau-eld et al, 2005). Dental caries is one of the main oral health problems in both industrialized and more so in the developing countries, affecting $60 \%-90 \%$ of school-aged children and adults (Peterson et al, 2005). Many of the developing countries reported higher prevalence of dental caries amongst higher socioeconomic classes than when compared to the lower SEC's, which was attributed to dietary factors. (Henshaw, 1974; Serwint et al,) (4) In summary, with strong evidence supporting the association of dental caries with irregular dietary patterns, quality, and the fact that abnormal dietary intake has been linked to the development of obesity at a young age, a link between dental caries and 
weight is biologically plausible. Hence, the aim of this preliminary study was to evaluate the association between obesity and dental caries.

\section{MATERIALS AND METHODS}

The present study was conducted amongst 70 out patients, 35 male and 35 female, visiting Saveetha Dental College, Chennai. The height of the subjects was calculated using a standard inch tape in Centimeters, and the weight was measured using a unicaliberated weighing machine in KiloGrams. The Body Mass Index of the subjects were then calculated using the height and weight, $\mathrm{BMI}=$ weight/(height $)^{2}$. Each patient was examined under proper lighting with the help of a mouth mirror and explorer for dental caries. Dental floss was made use of to check for proximal caries. Keil, Palmer and Knutson's DMFT index was used to assess dental caries status in the subjects. The collected data was then analysed using SPSS software.

\section{RESULTS}

In the current study a total of 70 patients 35 male and 35 female were screened. The mean age group of the subjects who participated was 35.92 . The mean DMFT index of all the participants was $5.85 .39 .4 \%$ of the participants were normal, $30.9 \%$ were overweight, $22.53 \%$ were obese and $7.04 \%$ were underweight (Graph:1).

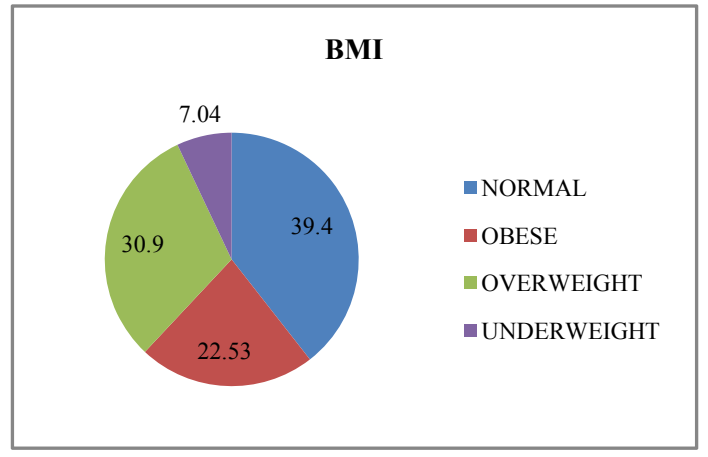

Graph 1 Prevalence of obesity amongst patients

Amongst those obese, $1.87 \%$ belonged to the age group of 21 $30,31.25 \%$ belonged to the age group of $31-40,31.25 \%$ belong to the age group $41-50$, and $18.75 \%$ belong to the age group 51-60 9 (Graph:2).

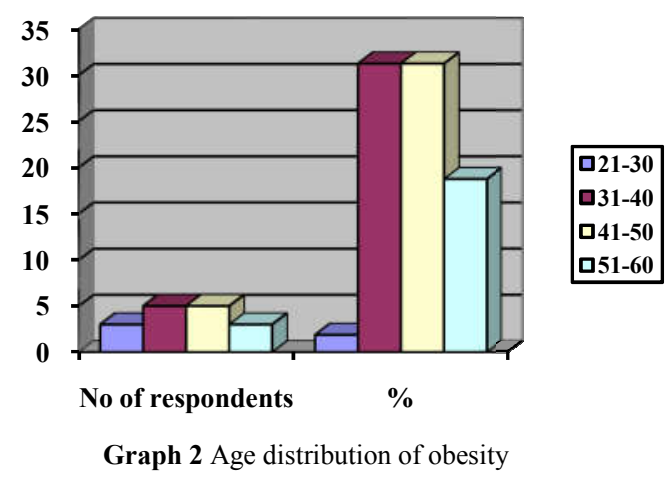

Pearson's correlation was done between the BMI status and the DMFT status of the participants and was found nonsignificant (Table:1). Pearson's correlation was also done between the DMFT status of the normal and obese (Table:2), normal and overweight (Table:3), obese and overweight (Table:4) and was found to be insignificant.

\section{Correlations}

\begin{tabular}{cccc}
\hline & & \multicolumn{2}{c}{ BMI DMFT index } \\
\hline \multirow{3}{*}{ BMI } & Pearson Correlation & 1 & .168 \\
& Sig. (2-tailed) & & .549 \\
& $\mathrm{~N}$ & 15 & 15 \\
\multirow{5}{*}{ DMFT index } & Pearson Correlation & .168 & 1 \\
& Sig. (2-tailed) & .549 & \\
& $\mathrm{~N}$ & 15 & 15 \\
\hline
\end{tabular}

Table 1 Correlation between DMFT index \& BMI

\begin{tabular}{ccccc}
\hline & & DMFT index & Obese & Normal \\
\hline \multirow{2}{*}{ DMFT index } & Pearson Correlation & 1 & .055 & -.162 \\
& Sig. (2-tailed) & & .845 & .563 \\
\multirow{5}{*}{ Obese } & N & 15 & 15 & 15 \\
& Pearson Correlation & .055 & 1 & -.004 \\
& Sig. (2-tailed) & .845 & & .988 \\
\multirow{5}{*}{ Normal } & N & 15 & 15 & 15 \\
& Pearson Correlation & -.162 & -.004 & 1 \\
& Sig. (2-tailed) & .563 & .988 & \\
& $\mathrm{~N}$ & 15 & 15 & 15 \\
\hline
\end{tabular}

Table 2 Correlation between DMFT index in obese \& normal subjects

\begin{tabular}{ccccc}
\hline & & DMFT index & Normal & Overweight \\
\hline \multirow{2}{*}{ DMFT } & Pearson Correlation & 1 & -.162 & -.119 \\
index & Sig. (2-tailed) & & .563 & .674 \\
& N & 15 & 15 & 15 \\
\multirow{5}{*}{ Normal } & Pearson Correlation & -.162 & 1 & .437 \\
& Sig. (2-tailed) & .563 & & .103 \\
& N & 15 & 15 & 15 \\
Overweight & Pearson Correlation & -.119 & .437 & 1 \\
& Sig. (2-tailed) & .674 & .103 & \\
& N & 15 & 15 & 15 \\
\hline
\end{tabular}

Table 3 Correlation between DMFT index of normal \& overweight subjects

\section{Correlations}

\begin{tabular}{ccccc}
\hline & & DMFT index & Overweight & Obese \\
\hline \multirow{5}{*}{ DMFT index } & Pearson Correlation & 1 & -.119 & .055 \\
& Sig. (2-tailed) & & .674 & .845 \\
& N & 15 & 15 & 15 \\
Overweight & Pearson Correlation & -.119 & 1 & -.125 \\
& Sig. (2-tailed) & .674 & & .658 \\
& N & 15 & 15 & 15 \\
Obese & Pearson Correlation & .055 & -.125 & 1 \\
& Sig. (2-tailed) & .845 & .658 & \\
& N & 15 & 15 & 15 \\
\hline
\end{tabular}

\section{DISCUSSION}

Dental caries is one of the most frequently citied infections of the oral cavity in routine clinical practice. The study of dental caries the multifactorial nature of the disease makes understanding the disease a baffling task. Dietary alterations is one of the most important risk factor for dental caries, and also the link between obesity and dental caries in a triangular relationship. Due to the lifestyle changes in the past few years and the alarming rise in the obesity rates, it is essential to understand the relationship between the two diseases. As the population in an hospital are diverse and represent the area it is present in, the study was done in a hospital. Most of the study participants belonged to lowers socio-economic status as per the trends of the hospital.

In the present study, $7.04 \%$ of the population was underweight, $39.4 \%$ of the population was normal, $30.9 \%$ was overweight and $22.54 \%$ was obese. Amongst those obese maximum were found to be of the age group 31-40 years $(31.25 \%)$ and $41-50 y e a r s$ (31.25\%), followed by 51-60years $(18.75 \%)$ and the least belonged to $21-30$ years $(1.87 \%)$. 
These trends in obesity were in accordance with previous studies. $(5,6)$.

In the present study the mean DMFT index was 5.83, which is considered high according to WHO criteria. This could be because of the reduced amounts of oral health awareness amongst the study population. The current study showed no evidence of association between BMI and dental caries. This is in accordance with previous studies $(5,7)$. Although there are a few studies that have found an association between the two criteria $(8,9)$. The results of the study can be justified by the fact that frequent consumption of cariogenic food is the only link between the two multifactorial entities.

Dental caries is a disease that causes the demineralisation of the tooth surface by the acids produced by carbohydrate fermenting bacteria in the oral cavity. Proper oral hygiene plays a very critical role in the initiation of a carious lesion $(10,11)$. Hence, although the increased tendency to snack is common in both, it is not sufficient to form a strong association.

This study did not comprise a questionnaire regarding the dietary habits and oral hygiene habits of the participants. The participants were not questioned about their personal habits such as tobacco smoking, pann chewing ect. The genetic basis for obesity was not considered in the study.

\section{CONCLUSION}

In the present study the mean DMFT index of all the participants was $5.85 .39 .4 \%$ of the participants were normal, $30.9 \%$ were overweight, $22.53 \%$ were obese and $7.04 \%$ were underweight. There was no association found between dental caries and Body Mass Index in the present study. Though there were previous studies conducted that have established a relationship between the two entities our result was negative. This could be because of the change in the ethnicity of the population or could be due to the small sample size. More research needs to be performed in these areas to better prevent the rise of these diseases.

\section{References}

1. Thakur JS. Emerging epidemic of non communicable diseases-an urgent need for control initiative. Indian $J$ Community Med 2005; 30:4.

2. Puska P, Nishida C, Porter D. Global strategy on diet, physical activity and health. Geneva: World Health Organization; 2003.

3. The growing problems of dental caries and obesity: an Australian perspective M. S. Hopcraft \& S. Beaumont; British Dental Journal 221, 379 - 381 (2016) Published online: 7 October 2016 | doi:10.1038/sj.bdj.2016.723

4. Association Between Obesity, Dental Caries and Socioeconomic Status in 6- and 13-year-old School Children; Basha Sakeenabi/Hiremath Shivalinga Swamy/Roshan Noor Mohammed.

5. Shakeel Anwar, Khalid Rehman, Misri Khan, Rasheed Afridi. Body Mass Index and Dental Caries. JKCD June 2013, Vol. 3, No. 2

6. Goodson JM, Tavares M, Wang X, Niederman R, Cugini M, et al. (2013) Obesity and Dental Decay: Inference on the Role of Dietary Sugar. PLoS ONE 8(10): e74461. doi:10.1371/journal.pone.0074461

7. Chen W, Chen P, Chen SC, Shin WT, Hu HC. Lack of association between obesity and dental caries in threeyear- old children. Zhonghua Min Guo Xiao ErKe Yi Xu-eHuiZaZhi. 1998; 39(2): 109-11

8. Khaled Alswata, c, Waleed S. Mohameda, Moustafa A. Wahabb, Ahmed A. AboelilbThe Association Between Body Mass Index and Dental Caries: Cross-Sectional Study. J Clin Med Res. 2016;8(2):147-152

9. Larsson B, Johansson I, Weinehell L, Hallmans G, Ericson T. Cardiovascular disease risk factors and dental caries in adolescents: effect of a preventive program in Northern Sweden (the Norsjo project) Acta Paediatr.1997; 86(1): 63-71

10. Fejerskov O, Kidd EAM, eds Dental Caries: the disease and its clinical management. Copenhagen, Denmark: Blackwell Monksgaard; 2003.

11. Marsh P, Martin M. Oral microbiology. 4th edition ed. Oxford: Wright; 1999.

\section{How to cite this article:}

Samyukta S and Gifrina Jeyraj (2017) ' Interrelationship Between Obesity And Dental Caries- A Pilot Study', International Journal of Current Advanced Research, 06(04), pp. 3063-3065.

DOI: http://dx.doi.org/10.24327/ijcar.2017.3065.0182 